\title{
Patient Perspectives on Novel Treatments in Haemophilia: A Qualitative Study
}

\author{
Erna C. van Balen ${ }^{1}$ (1) $\cdot$ Marjolein L. Wesselo ${ }^{1,2} \cdot$ Bridget L. Baker $^{1,2} \cdot$ Marjan J. Westerman $^{2}$ (1) $\cdot$ Michiel Coppens ${ }^{3}$. \\ Cees Smit ${ }^{1} \cdot$ Mariëtte H. E. Driessens $^{5} \cdot$ Frank W. G. Leebeek $^{6}$. Johanna G. van der Bom ${ }^{1,7}$ (D) Samantha C. Gouw ${ }^{1,4}$
}

Published online: 6 November 2019

(c) The Author(s) 2019

\begin{abstract}
Background and Objective New treatments for haemophilia are under development or entering the market, including extended half-life products, designer drugs and gene therapy, thereby increasing treatment options for haemophilia. It is currently unknown how people with haemophilia decide whether to switch to a new treatment. Therefore, the objective of this study was to explore what factors may play a role when Dutch patients and parents of boys with moderate or severe haemophilia make decisions about whether to switch to a different treatment, and how disease and treatment characteristics may affect these decisions. This may aid clinical teams in tailored information provision and shared decision making.

Methods We conducted interviews among adults with moderately severe or severe haemophilia and parents of young boys with severe haemophilia. We aimed to include participants from a variety of backgrounds in terms of involvement in the haemophilia community, age, treatment centre and treatments. Participants were recruited through the Netherlands Haemophilia Society and a haemophilia treatment centre. Semi-structured interviews were recorded and transcribed verbatim. Thematic content analysis was used to analyse the data.

Results Twelve people with haemophilia and two mothers of boys with haemophilia were included. In general, participants reported to be satisfied with their current treatment. However, they considered ease of use of the medication (fewer injections, easier handling, alternative administration) an added value of new treatments. Participants were aware of the high cost of coagulation factor products and some expressed their concern about the Netherlands Haemophilia Society's long-term willingness to pay for current and novel treatments, especially for increased usage due to high-risk activities. Participants also expressed their concerns about the short- and long-term safety of new treatments and believed the effects of gene therapy were not yet fully understood. Participants expected their treatment team to inform them when a particular new treatment would be suitable for them.

Conclusions With the number of treatment options set to increase, it is important for healthcare providers to be aware of how patient experiences shape patients' decisions about new therapies.
\end{abstract}

\section{Introduction}

Haemophilia is a rare congenital coagulation disorder caused by a deficiency in either factor VIII (haemophilia A) or factor IX (haemophilia B), affecting 1 in 10,000 live births [1]. Haemophilia is classified into severe haemophilia $(<1 \%$ of normal), moderate haemophilia (1-5\% of normal) and mild

Electronic supplementary material The online version of this article (https://doi.org/10.1007/s40271-019-00395-6) contains supplementary material, which is available to authorized users.

Samantha C. Gouw

S.C.Gouw@lumc.nl

Extended author information available on the last page of the article

\section{Key Points}

In addition to injection frequency, bleed control and infection risk, costs of treatment may play a role in decisions about novel therapies.

People with haemophilia appreciate information about new therapies from both the Netherlands Haemophilia Society and their treating physician. They expect their treatment team to inform them about specific new products that are suitable for them. 
haemophilia (5-40\% of normal) [1, 2]. The lack of coagulation factor VIII or IX causes spontaneous bleeds in patients with severe haemophilia, mainly into joints and muscles, causing debilitating and painful joint damage [3]. Treatment has evolved from whole blood transfusions prior to the 1960s to modern concentrated recombinant factor VIII and IX products. The deficient coagulation factor is administered two to three times a week by an intravenous injection to prevent bleeds (prophylaxis). Unfortunately, many people with haemophilia were infected with human immunodeficiency virus and/or hepatitis $\mathrm{C}$ virus through whole blood products in the 1980s and early 1990s [1, 4]. In the last few years, products with an extended half-life (requiring less frequent administration) have become available. The availability of treatment has improved the life expectancy of people with haemophilia [5] and decreased bleeding rates and joint impairment [6].

Despite these advancements [6], a cure for haemophilia is not widely available yet and current treatment is still far from optimal. According to patients, products could be improved for frequency of administration [7], efficacy of coagulation products (preventing bleeds) [8], mode of administration [7], easier storage [7, 8], fewer side effects (potential transmission of pathogens, antibodies against infused factor VIII or IX) and packaging (size, components of medication, logistics) $[7,8]$. Intravenous infusion of coagulation factor may pose a problem, especially for young children with delicate veins or for older people, for example, owing to an increased difficulty in self-administration with increasing age [9].

New treatments are under development or have recently been marketed that aim to address the disadvantages mentioned above, such as products with an extended half-life, gene therapy and products that affect the coagulation cascade through different mechanisms than replacing the absent coagulation factor. Some of these products may be administered subcutaneously and no longer require intravenous injections. However, new treatments may have drawbacks of their own, including known and unknown risks, as summarised in Table 1 [10-14].

The Netherlands is a small country with high-quality healthcare and social security systems. The cost of coagulation factor is covered under public health insurance, with a deductible for specialist care. Several factor VIII and factor IX products are available to patients and providers. People with haemophilia receive care from one of six Dutch Haemophilia Treatment Centers and most people with severe haemophilia attend their clinic appointment annually.

It is currently not sufficiently known which factors play a role in patients' decisions about whether switch to a new therapy. Previous internet surveys conducted in Australia, Canada, USA and Sweden reported that the frequency of clotting factor treatment administration $[15,16]$, efficacy to prevent bleeds [15, 16], manufacturer of the product [15] and shared decision making [16] were important to patients. Finally, a study in Germany, Austria and Switzerland found that parents were more hesitant to switch to an extended half-life product than patients [8]. However, these questionnaires mostly presented a finite number of factors that may play a role in decision making. Questionnaires also provide little information on how individuals' personal backgrounds (e.g. age) and their disease and treatment characteristics and experiences (e.g. bleed history, experience with selfadministration of coagulation factor, history of blood-borne infections) may affect decision making. A better understanding of all factors that may play a role in decisions about treatment (both treatment and personal characteristics) will help haemophilia care providers provide tailored information when making shared decisions on the optimal management strategy of haemophilia [17, 18], all of which are elements of patient-centred care [19-21]. Therefore, we aimed to explore what factors may play a role when Dutch patients and parents of boys with moderate or severe haemophilia make decisions about whether to switch to a different treatment, and how disease and treatment characteristics may affect these decisions.

\section{Methods}

\subsection{Study Design}

We conducted a qualitative study among people with haemophilia A or B or parents of young boys with haemophilia A or B, using interview methods. We aimed to include participants with varying involvement in the haemophilia community, age, and treatment centre, and in the dosing, type and frequency of treatment (purposive sampling) [22]. Prior to the interviews, topic lists were prepared based on literature and clinical experience. These included questions about current and novel treatments, the burden of haemophilia, and its treatment and involvement in decision making. Interview questions were revised iteratively after each interview so that new interesting issues that were raised could be explored in future interviews [23]. The topic list is included in the Electronic Supplementary Material.

\subsection{Recruitment and Data Collection}

Participants were approached through the Netherlands Haemophilia Society by an advertisement in a private Facebook group moderated by the Society and the quarterly e-mail newsletter to members. Participants were also approached with an invitation letter of the haemophilia outpatient clinic of the Amsterdam University Medical Centers, the Netherlands, or through word of mouth. After a positive response, 


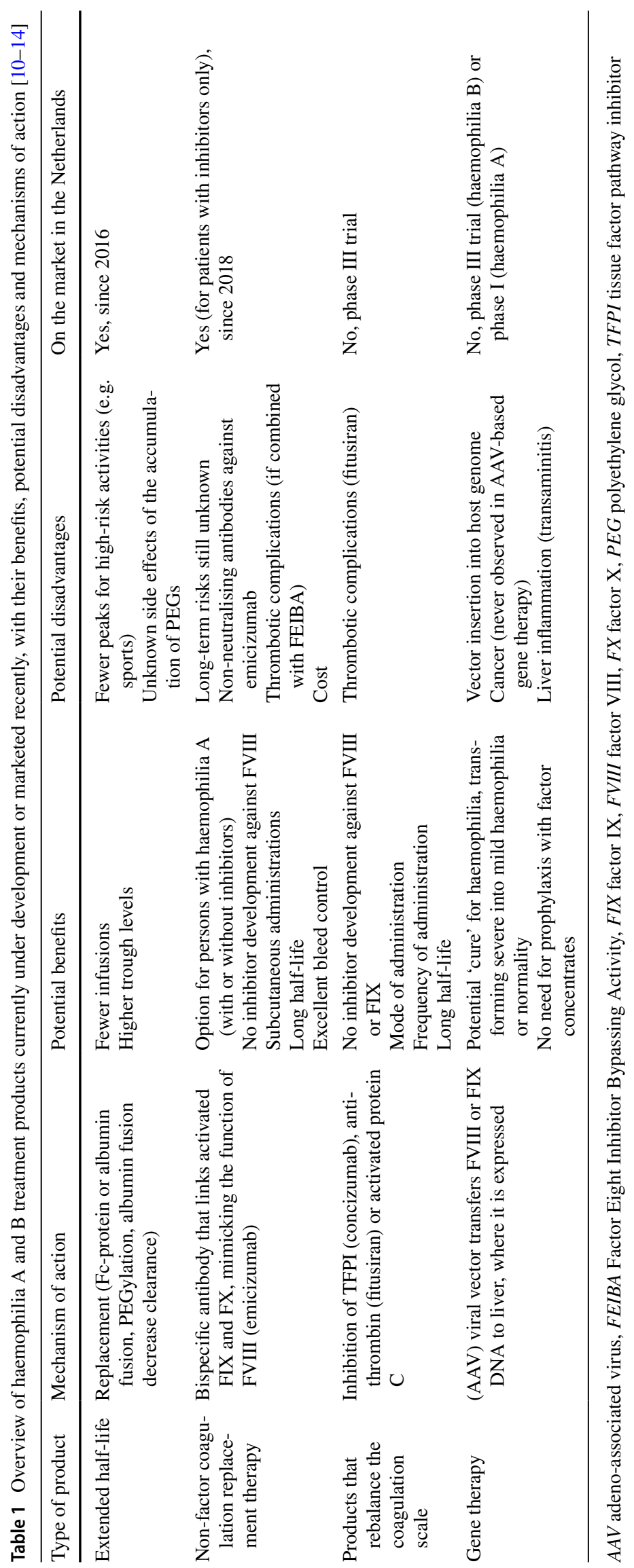


interviewers introduced themselves over the phone and an appointment was established.

BB and MLW, undergraduate students in health sciences with some experience in interviewing, conducted semistructured interviews between March and December 2017 at the participants' homes. The number of interviews was pre-determined to be 12-14. A sample size of $12-15$ is considered sufficient to understand participants' experiences in thematic content analysis [23]. Interviews lasted between 37 and $82 \mathrm{~min}$ and were audio-recorded and transcribed verbatim.

\subsection{Analysis}

Thematic content analysis [23] was used to analyse the data. All interview transcripts were initially coded using open coding with the software program MAXQDA version 12 (http://www.maxqda.com). Three researchers (EvB, BB, MLW) discussed codes and agreed on a coding scheme, which was then applied to all transcripts. Codes were organised into main topics and reorganised into themes that were relevant to the research question, creating a thematic map. This map consisted of themes related to experiences with current and past treatment, reasons for whether to switch to new treatment options and sources of information for these decisions. Within themes, we looked for differences and similarities between participants. The authors EvB, JvdB, SG and MJW discussed final codes and themes. Quotes were extracted to illustrate aspects of themes using participants' own words.

\subsection{Ethics}

Exemption from full dossier ethical approval was obtained from the Research Ethics Board of the Amsterdam University Medical Centers. All participants provided written informed consent.

\section{Results}

\subsection{Participants}

Of 14 individuals who participated, 12 had moderate or severe haemophilia. Two were mothers of children with severe haemophilia (aged 7 and 10 years). The 14 participants reflected a variety of the Dutch population with moderate and severe haemophilia in terms of age, treatment centre, needle fear, human immunodeficiency virus and hepatitis $\mathrm{C}$ virus infection status, perceived involvement in decision making and membership of the Netherlands Haemophilia Society (Table 2). Thirteen participants were receiving home treatment (12 prophylaxis, one on-demand). One participant did not self-infuse but visited the hospital when he had a bleed. All used standard half-life recombinant coagulation factor products.

The results are described in three themes: (1) current treatment, experiences and perspectives, (2) factors related to deciding to switch to a new therapy and (3) sources of information regarding novel treatments.

\subsection{Current Treatment, Experiences and Perspectives}

Experiences with current treatment were mostly positive, but self-administering treatment was sometimes described as a challenge. In general, participants reported that current coagulation factor treatment was easy to administer, safe and effective in preventing bleeds. Younger participants reported it had always been part of their daily lives. However, older participants remembered that in the past, treating themselves was more burdensome than currently because of the larger volume of past products, the need to carefully mix components of the medication and the longer time it required to infuse intravenously. They appreciated how much easier administration had become. Those taking prophylaxis all reported that they adjusted their infusion schedules depending on their daily activities, but considered themselves adherent.

Three individuals in their 60s and 70s (P1, P2 and P8) said injecting at home had become more difficult in recent years because of scarring of the injection site or reduced eyesight. Participants 8 and 13 commented that self-infusing could be 'a hassle', and participant 8 found ordering, picking up and storing the treatment product quite an effort. Two participants sometimes experienced slipping of the needle from the injection site. One of the mothers said she sometimes felt pressure to perform the venipuncture when her son had an acute bleed.

All participants were aware that new treatments had recently become available or were under development. Despite the challenges they described with their current treatment, they said they did not need new products for themselves, but welcomed this development.

Many participants were aware of the high costs and tried to use their products responsibly. Eight participants (six on prophylaxis, two on-demand) spontaneously mentioned the current high costs of their coagulation factor products. The six participants who were asked about costs were aware that their treatment was expensive. Interestingly, six participants (three taking on-demand treatment) reported that they avoided injections when possible to save costs for the healthcare system, against their physician's advice to take their coagulation factor when they needed it.

Participants were grateful that the cost of their coagulation factor was covered by the healthcare system. Some 
Table 2 Participant characteristics

\begin{tabular}{|c|c|c|c|c|c|c|c|}
\hline $\begin{array}{l}\text { Par- } \\
\text { ticipant } \\
\text { number }\end{array}$ & $\begin{array}{l}\text { Age group }{ }^{a} \text {, } \\
\text { years }\end{array}$ & $\begin{array}{l}\text { Severity and type } \\
\text { of HA }\end{array}$ & $\begin{array}{l}\text { Type of product } \\
\text { (standard half- } \\
\text { life recombinant } \\
\text { coagulation fac- } \\
\text { tor concentrate) }\end{array}$ & $\begin{array}{l}\text { Reported needle } \\
\text { fear }\end{array}$ & $\begin{array}{l}\text { HIV or HCV } \\
\text { infection }\end{array}$ & $\begin{array}{l}\text { Perceived } \\
\text { involvement } \\
\text { in decision } \\
\text { making }^{\mathrm{b}}\end{array}$ & $\begin{array}{l}\text { Member of Neth- } \\
\text { erlands Haemo- } \\
\text { philia Society }\end{array}$ \\
\hline $\mathrm{P} 1$ & $65-70$ & Severe HA & $\begin{array}{l}\text { Prophylaxis, } \\
500 \text { IU daily }\end{array}$ & No & HCV (cleared) & Yes & Yes \\
\hline $\mathrm{P} 2$ & $70-75$ & Severe HA & $\begin{array}{l}\text { Prophylaxis, } \\
1000 \text { IU, } 2 \\
\text { times per week }\end{array}$ & Yes & $\mathrm{HCV}$ & No & Yes \\
\hline P3 & $25-30$ & Severe HB & $\begin{array}{l}\text { Prophylaxis, } \\
1000 \text { IU, once } \\
\text { every 4-5 days }\end{array}$ & No & HCV (cleared) & Yes & Yes \\
\hline P4 & Child $<12$ & Severe HA & $\begin{array}{l}\text { Prophylaxis, } \\
750 \text { IU, } 3 \text { times } \\
\text { per week }\end{array}$ & Sometimes & None & No & Yes \\
\hline P5 & $65-70$ & $\begin{array}{l}\text { Moderate-severe } \\
\text { HA }\end{array}$ & $\begin{array}{l}\text { On-demand } \\
\text { (mild pheno- } \\
\text { type) }\end{array}$ & No & None & Yes & Yes \\
\hline P6 & Child $<12$ & Severe HA & $\begin{array}{l}\text { Prophylaxis, } \\
500 \text { IU, } 3 \text { times } \\
\text { per week }\end{array}$ & No & None & Yes & Yes \\
\hline P7 & $40-45$ & Severe HA & $\begin{array}{l}\text { Prophylaxis, } \\
2000 \text { IU, every } \\
\text { other day }\end{array}$ & No & HCV (cleared) & Sometimes & Yes \\
\hline P8 & $60-65$ & Severe HA & $\begin{array}{l}\text { Prophylaxis, } \\
1000 \text { IU, } 3 \\
\text { times per week }\end{array}$ & No & HCV (cleared) & No & Yes \\
\hline P9 & $20-25$ & Severe HA & $\begin{array}{l}\text { Prophylaxis, } \\
1000 \text { IU, 2-3 } \\
\text { times per week } \\
\text { (but irregular) }\end{array}$ & No & None & Yes & No \\
\hline $\mathrm{P} 10$ & $60-65$ & $\begin{array}{l}\text { Moderate-severe } \\
\text { HA }\end{array}$ & $\begin{array}{l}\text { On-demand } \\
\text { (mild pheno- } \\
\text { type) }\end{array}$ & Unknown & HCV (cleared) & No & Yes \\
\hline P11 & $55-60$ & Severe HA & $\begin{array}{l}\text { On-demand } \\
\text { (mild pheno- } \\
\text { type) }\end{array}$ & No & $\begin{array}{l}\text { HCV (cleared), } \\
\text { HIV }\end{array}$ & No & No \\
\hline P12 & $35-40$ & Severe HB & $\begin{array}{l}\text { On-demand } \\
\text { (mild pheno- } \\
\text { type) }\end{array}$ & No & $\mathrm{HCV}$ & No & No \\
\hline P13 & $25-30$ & Severe HA & $\begin{array}{l}\text { Prophylaxis, } \\
1500 \text { IU, every } \\
\text { other day (but } \\
\text { irregular) }\end{array}$ & No & None & No & Yes \\
\hline P14 & $55-60$ & Severe HA & $\begin{array}{l}\text { Prophylaxis, } \\
1000 \text { IU daily }\end{array}$ & No & HCV (cleared) & No & No \\
\hline
\end{tabular}

$H A$ haemophilia $\mathrm{A}, H B$ haemophilia $\mathrm{B}, H C V$ hepatitis $\mathrm{C}$ virus, $H I V$ human immunodeficiency virus, $I U$ international units aParticipants' ages are presented in age groups to protect their privacy

${ }^{b}$ Participants were asked whether they felt they were involved the decision making about product and dose

were concerned about a perceived societal trend in which patients are increasingly responsible for their own healthcare costs. Participant 2, for example, remembered that sufficient amounts of coagulation factor were not always available in the past:
"It is a concern to me, because I can imagine [...] that treatment will become scarce again. [The availability of] treatment is not a given if costs get out of control. We are dependent on the solidarity of society" 
Furthermore, three of the older participants (P1, P2 and P8) expressed their concerns about younger patients engaging in physical activities such as skiing, soccer and mountain biking because of the costs for society of the increased prophylactic coagulation factor usage. They thought the availability of haemophilia treatment may ultimately depend on society's willingness to pay for this increased usage. However, one of the mothers and four other younger participants said practising sports should be possible for persons with haemophilia provided they were careful and used prophylaxis. One young participant wondered about the costs of new extended half-life products:

"You would save a lot of injections [with EHL products], and I don't know whether that would outweigh the higher costs of [this] new product. I don't mind the injections, I don't mind to infuse a bit more often, [...] I wouldn't necessarily want to do that [higher cost] to society". (participant 3)

\subsection{Factors Related to Deciding to Switch to a New Therapy}

When asked, eight participants were open to trying new treatments (although some felt they did not urgently need them). Three younger participants (P9, P12, P13) with few bleeding problems (two taking prophylaxis with irregular schedules, one on-demand) did not feel the need to switch because they were satisfied with their current treatment. The two mothers expressed a wait-and-see attitude for novel treatments because at the time of their interviews they thought new treatments would not be available soon, and they did not want to be the first to try a new therapy because of potential unknown risks.
Decisions on whether to switch to a new therapy were multifactorial and not self-evident. Factors that may play a role in these decisions are summarised in Table 3. Facilitating factors were improved ease of use of medication and better efficacy. Barriers were fear of unknown (short and long term) safety and efficacy, and not wanting to be a research subject if there were risks involved. Below, we highlight some factors that shape participants' treatment decisions and describe them in more detail: ease of use of the medication and fear of the unknown.

\subsubsection{Facilitator: Ease of Use of the Medication}

A majority of eight participants (of whom seven had been co-infected) mentioned that they preferred to inject less frequently. Three young adults (participants P3, P9 and P13) who reported no problems with their current injection schedules viewed fewer injections as an added value to new therapies that they were looking forward to, but they did not consider fewer injections to be absolutely necessary for them. They each mentioned an example of others for whom extended half-life products with lower injection frequency would be especially valuable: for children, for a brother who was not as adherent or for others who had more bleeds. Participant 1 reported looking forward to being able to inject every 3 days instead of daily, which he expected to be a reality in 5 years. For another older participant (P2) with a hepatitis $C$ virus infection in the past, each injection meant a presumed infection risk and for this reason he was looking forward to any reduction in injection frequency.

Participants 3 and 12 would prefer a cure for haemophilia instead of fewer injections, although they said they had few bleeding problems. Furthermore, participant 8 , who was reluctant to switch because of his experiences with hepatitis

Table 3 Factors that may play a role in making decisions about switching to new therapies

\begin{tabular}{|c|c|c|}
\hline Reason & Barrier/facilitator & Key points \\
\hline Ease of use of the medication & Facilitator & $\begin{array}{l}\text { The ease of use of the medication could be improved by: } \\
\text { Easier to carry, store and mix } \\
\text { Less frequent injections, or a (perceived) lack of need for injections alto- } \\
\text { gether with a cure } \\
\text { Alternatives for intravenous injections: other locations for injecting (subcu- } \\
\text { taneous) or alternative administration routes (tablet or nasal spray) }\end{array}$ \\
\hline Equally good or better bleed prevention & Facilitator & $\begin{array}{l}\text { A new therapy should: } \\
\text { Provide protection against bleeds that is at least as good or even better than } \\
\text { their current therapy } \\
\text { Have sufficiently high peak and trough levels }\end{array}$ \\
\hline Fear of the unknown & Barrier & $\begin{array}{l}\text { Participants were concerned about still undiscovered transmittable patho- } \\
\text { gens and antibody development. For gene therapy, they were concerned } \\
\text { about long-term safety of the therapy and thought these effects were not } \\
\text { yet fully understood }\end{array}$ \\
\hline Do not want to be a guinea pig/research subject & Barrier & $\begin{array}{l}\text { Participants felt uncomfortable to participate in a trial because of unknown } \\
\text { risks or being the first to try a new therapy }\end{array}$ \\
\hline
\end{tabular}


$\mathrm{C}$ virus treatment in the past, commented that he would only switch if the frequency of injections of extended half-life products was considerably lower:

"If I had to switch to a different medication, I would switch to one with a longer half-life. That would be a bit better for me so I have to inject less often. But the savings [in half-life] are not that big [...], from 14 to 17 hours. I didn't think that was very impressive. For that reason I have not switched this time."

Other reasons participants wanted to inject less frequently were the effort it required to plan injections and carry and store their coagulation factor products. For example, participant 12 travelled frequently for work and thought the packaging should be easier to carry with him. Participant 13 proposed alternative locations for his intravenous injections, such as a finger or a thigh. When asked about their recommendations for drug development companies, several participants also suggested different administration routes such as a tablet, a nasal spray, an ingestible nanotube with coagulation factor or a subcutaneous device.

\subsubsection{Barrier: Fear of the Unknown}

A few participants were concerned about potential risks of new coagulation factor products, such as inhibitor development and potential undiscovered transmittable pathogens. For extended half-life products, participants 8 and 3 expressed their concerns about having a low trough level for a longer time than with standard half-life products, making them more vulnerable to bleeds. A young participant (P3) was not convinced safety was properly studied. However, he and one of the mothers were willing to try an extended halflife product because they thought they could always return to the standard half-life product.

Many participants thought gene therapy was promising, but they were also concerned about its long-term safety and the risks of adverse effects.

"It's a virus that you inject in your body, which may cause a liver infection, which would have to be inhibited with corticosteroids.[...] On the other hand, it's such a temporary side effect, and if you benefit from that the rest of your life ..." (participant 3)

An older participant (P2) said he was hesitant to switch to a new treatment because he currently used a product that was effective in controlling bleeds, and he did not want to risk replacing his current treatment for one with uncertain effects. He considered the experience of two others with haemophilia who had undergone gene therapy as part of a trial in his decision:
"I know two guys that participated in a gene therapy trial. One was out of luck, he didn't achieve higher factor levels. The other one did. Yes, fantastic if it works. [But] they don't know it yet. [...] So you have to ask yourself ... [...] it would be a pure gain if it works. On the other hand, if you have good treatment, why would you change it?" (Participant 2)

When asked, participants often mentioned they wanted to be well informed about possible risks and side effects when making decisions about new treatments.

\subsection{Sources of Information Regarding Novel Treatments}

Participants reported that their most important source of information was their physician or nurse. Six of them (all age groups, members and non-members, different perceptions of involvement in decision making) said they discussed the development of new therapies with their treatment team during their clinic appointment and trusted that their physician would inform them at the time a particular new treatment was suitable for them.

"The doctors are specialists [...] and at some point they'll say: 'hey, we have this new treatment for you', so I'll say: 'sure, bring it on!'” (participant 11)

Those who were members of the Netherlands Haemophilia Society also expected the society to provide information about the types of treatment that are under development. Participants regularly received information from this source, for example, from annual general meetings, the Netherlands Haemophilia Society's website, Facebook page, annual camping weekend and their biannual magazine. Some participants were active in the Facebook group and used it to exchange experiences with peers. Participant 11, however, was not particularly interested in the information provided by the Netherlands Haemophilia Society.

A few people also searched for information on the internet. However, participant 14 said it was difficult to know what terms to search for and participant 8 said information from other countries, with their different care settings, was difficult to apply to his own situation.

\section{Discussion}

In our interview study, we found that people with moderate or severe haemophilia and parents of young boys with haemophilia were generally satisfied with their current treatments. They considered different aspects of novel treatments important in their treatment decisions, including ease of use of the medication, better bleed control and safety. However, 
some participants shared concerns about unknown risks of new therapies. As an additional finding, the financial burden of current treatment on the healthcare system appeared to be a concern for a few participants because they felt societal willingness to pay might not be a given in the future. Participants wished to receive information about new treatments, including their risks and benefits from the Netherlands Haemophilia Society as well as their haemophilia treatment team.

Previous studies have identified similar considerations of persons with haemophilia as important features of extended half-life products $[8,16]$. For example, in assessing a series of hypothetical treatment scenarios with three treatment attributes each (injection interval, participation in physical activity, annual risk of bleed), patients and parents of boys with haemophilia ranked bleed control as the most important [16]. Another questionnaire study about expectations and concerns of extended half-life products reported injection frequency to be the most important feature of these products [8]. Our study enriched this knowledge by describing the reasons for the desire for a lower injection frequency: a presumed infection risk, planning injections and not having to carry and store treatment products. Interestingly, many participants considered themselves adherent even though they skipped infusions, and found treatment products with a lower injection frequency especially suitable for 'others'.

An interesting finding is that the societal financial burden of current haemophilia treatment is a concern for some participants. Costs of current treatment have been identified as an important feature of haemophilia treatment in previous discrete-choice experiments that aimed to elicit patient preferences [24, 25]. Several participants in our study tried to save costs for the healthcare system. Older participants appeared to be more conservative in allowing people with haemophilia to engage in high-risk activities than younger participants. Unlike older generations, younger participants grew up with treatment available and may therefore consider it a given. One participant spontaneously mentioned his concern for the cost of new therapies specifically. Given that the costs of current treatment were important to most participants, it is probable that costs also play a role in decisions about novel therapies. In the Netherlands, the cost of coagulation factor is covered by the healthcare system, but all participants in our sample were aware of the high costs and some even tried to save costs by avoiding self-infusion, even when they had a bleed. Possibly, recent media attention surrounding health technology assessments, pricing and reimbursement decisions for expensive drugs in rare diseases may have shaped participants' opinions [26]. Costs of future novel treatment options, for example of gene therapy, are still unknown, making this difficult to address in patient-clinician interactions. However, it may be of value to patients if healthcare providers are able to share what they know about the costs of current and future treatments.

Knowledge about which features of novel treatments are important, including real and perceived risks such as pathogen transmission, may help the haemophilia treatment team tailor information provision and patient education efforts. To structure this information in these interactions, a shared decision-making tool may be used. An interactive digital platform may further personalise information provision. Our findings may serve as a starting point for the contents of a shared decision-making tool. We suggest to explore this further in focus groups of patients and caregivers of patients.

\subsection{Strengths and Limitations}

A strength of our study is that it included a variety of perspectives on new treatments, illustrated by quotes. We purposively included people of different ages, including parents of young boys, and with varying involvement in the haemophilia community (active or no membership of the Netherlands Haemophilia Society). This was done because we presumed differences in the knowledge of new treatments. We also considered it important to include parents of young boys with haemophilia to explore how they viewed treatment decisions for their sons. Although the disease context of mothers is different from that of patients, we included them because they are responsible for making treatment decisions on behalf of their sons. In line with previous research [8], the mothers in our sample were somewhat more hesitant than patients to switch to a new treatment. Our study adds that this was because they preferred to wait for more information to become available on the effectiveness of these treatments.

A potential limitation may be that the first six participants responded to an advertisement through the Netherlands Haemophilia Society and therefore may have been better informed and more interested than average to discuss their views on treatment. Therefore, to obtain perspectives of representatives of the complete haemophilia community, the next eight participants were approached through the outpatient clinic at the Amsterdam University Medical Center. In both groups, participants knew about gene therapy and extended half-life products, but other options, such as bypassing agents or other non-factor replacement treatments, were not mentioned.

A second limitation may be that participants could have expressed a more positive satisfaction with their current treatment than their true experience. Participants were interviewed at their homes by two investigators relatively new to the field of haemophilia, and the experiences participants shared about their current treatment may have been more positive than what they would have shared with their own healthcare provider. However, our aim was not to elicit all possible problems participants may experience with their 
current treatment, but to explore the factors that may play a role in patients' and parents' decisions about current and new treatment options.

Last, extended half-life products and non-factor replacement products have become available in the past 2 years. It is possible that participants are now better informed about these novel therapies than they were at the time of their interviews. Participants' perceptions may have changed as a result of this: acceptability of newer products may have increased. However, we believe that many of the concerns expressed may be applicable to decisions on any type of treatment product switch, regardless of whether the switch is made to a novel therapy or an existing treatment.

\section{Conclusions}

New treatments for haemophilia are becoming available in the next few years, increasing the number of options patients and providers can choose from. Patients have a voice in these decisions. We confirmed previously identified barriers and facilitators that play a role in making these decisions, and added that costs of treatment may play a role. It is important for haemophilia treatment teams to be aware of these factors in providing information to facilitate shared decision making.

Acknowledgements We thank all the patients with haemophilia and the two mothers of children with haemophilia who participated in the interviews.

Author Contributions BLB conducted six interviews and created the initial coding scheme. MLW conducted eight interviews and revised the coding scheme. EvB and MJW supervised BLB and MLW in the design, analysis, and write-up of summaries and initial reports. MC, $\mathrm{MD}$ and CS assisted in recruiting participants for the study. EvB, JvdB, SG and MJW designed the study, discussed final codes and themes, and wrote the manuscript. All authors provided feedback on the manuscript and approved the final manuscript.

\section{Compliance with Ethical Standards}

Funding This study was funded by the Dutch Ministry of Health, Welfare and Sports as part of the Haemophilia in the Netherlands study.

Conflict of interest $\mathrm{MC}$ has received financial support for research, as well as lecturing and consultancy fees from Bayer, CSL Behring, Sanquin Blood Supply and UniQure. FL received an unrestricted research grant from CSL Behring and Shire (Takeda) and is a consultant for UniQure, CSL Behring and NovoNordisk of which fees go to the university. He is also a Data and Safety Monitoring Board member for a study conducted by Roche. JvdB has been a teacher on the educational activities of Bayer. EvB, MLW, BB, MJW, CS, MD and Samantha C. Gouw have no conflicts of interest that are directly relevant to the content of this article.

Data Availability The datasets generated during and/or analysed in the current study are not publicly available because of privacy-sensitive information included in the interview transcripts but are available from the corresponding author on reasonable request. Interview transcripts are in Dutch.

Ethics Approval Exemption from full dossier ethical approval was obtained from the Research Ethics Board of the Amsterdam University Medical Centers.

Consent to Participate All participants provided written informed consent.

Open Access This article is distributed under the terms of the Creative Commons Attribution-NonCommercial 4.0 International License (http://creativecommons.org/licenses/by-nc/4.0/), which permits any noncommercial use, distribution, and reproduction in any medium, provided you give appropriate credit to the original author(s) and the source, provide a link to the Creative Commons license, and indicate if changes were made.

\section{References}

1. Srivastava A, Brewer AK, Mauser-Bunschoten EP, Key NS, Kitchen S, Llinas A, et al. Guidelines for the management of hemophilia. Haemophilia. 2013;19(1):e1-47. https://doi.org/10. 1111/j.1365-2516.2012.02909.x.

2. Blanchette VS, Key NS, Ljung LR, Manco-Johnson MJ, van den Berg HM, Srivastava A. Definitions in hemophilia: communication from the SSC of the ISTH. J Thromb Haemost. 2014;12(11):1935-9. https://doi.org/10.1111/jth.12672.

3. Hoyer LW, Hemophilia A. N Engl J Med. 1994;330(1):38-47.

4. Franchini M, Mannucci PM. Past, present and future of hemophilia: a narrative review. Orphanet J Rare Dis. 2012;7:24.

5. Plug I, Van Der Bom JG, Peters M, Mauser-Bunschoten EP, De Goede-Bolder A, Heijnen L, et al. Mortality and causes of death in patients with hemophilia, 1992-2001: a prospective cohort study. J Thromb Haemost. 2006;4(3):510-6. https://doi.org/10. 1111/j.1538-7836.2006.01808.x.

6. Plug I, van der Bom JG, Peters M, Mauser-Bunschoten EP, de Goede-Bolder A, Heijnen L, et al. Thirty years of hemophilia treatment in the Netherlands, 1972-2001. Blood. 2004;104(12):3494500. https://doi.org/10.1182/blood-2004-05-2008.

7. Tischer B, Marino R, Napolitano M. Patient preferences in the treatment of hemophilia A: impact of storage conditions on product choice. Patient Prefer Adherence. 2018;12:431-41. https://doi. org/10.2147/ppa.s151812.

8. von Mackensen S, Kalnins W, Krucker J, Weiss J, Miesbach W, Albisetti M, et al. Haemophilia patients' unmet needs and their expectations of the new extended half-life factor concentrates. Haemophilia. 2017;23(4):566-74. https://doi.org/10.1111/ hae.13221.

9. Smith N, Bartholomew C, Jackson S. Issues in the ageing individual with haemophilia and other inherited bleeding disorders: understanding and responding to the patients' perspective. Haemophilia. 2014;20(1):e1-6. https://doi.org/10.1111/hae.12278.

10. Balkaransingh $P$, Young G. Novel therapies and current clinical progress in hemophilia A. Ther Adv Hematol. 2018;9(2):49-61. https://doi.org/10.1177/2040620717746312.

11. Evens H, Chuah MK, VandenDriessche T. Haemophilia gene therapy: from trailblazer to gamechanger. Haemophilia. 2018;24(Suppl. 6):50-9. https://doi.org/10.1111/hae.13494.

12. Mahlangu JN. Updates in clinical trial data of extended halflife recombinant factor IX products for the treatment of 
haemophilia B. Ther Adv Hematol. 2018;9(11):335-46. https:// doi.org/10.1177/2040620718802606.

13. Nathwani AC, Reiss UM, Tuddenham EGD, Rosales C, Chowdary $\mathrm{P}$, McIntosh J, et al. Long-term safety and efficacy of factor IX gene therapy in hemophilia B. N Engl J Med. 2014;371(21):1994 2004. https://doi.org/10.1056/NEJMoa1407309.

14. Oldenburg J, Mahlangu JN, Kim B, Schmitt C, Callaghan MU, Young G, et al. Emicizumab prophylaxis in hemophilia A with inhibitors. N Engl J Med. 2017;377(9):809-18. https://doi. org/10.1056/NEJMoa1703068.

15. Furlan R, Krishnan S, Vietri J. Patient and parent preferences for characteristics of prophylactic treatment in hemophilia. Patient Prefer Adherence. 2015;9:1687-94. https://doi.org/10.2147/ppa. s92520.

16. Steen Carlsson K, Andersson E, Berntorp E. Preference-based valuation of treatment attributes in haemophilia A using web survey. Haemophilia. 2017;23(6):894-903. https://doi.org/10.1111/ hae.13322.

17. Miesbach W, Sawyer EK. Practical implications of factor IX gene transfer for individuals with hemophilia B: a clinical perspective. Hum Gene Ther Clin Dev. 2018;29(2):80-9. https://doi. org/10.1089/humc.2017.253.

18. Lieuw K. Many factor VIII products available in the treatment of hemophilia A: an embarrassment of riches? J Blood Med. 2017;8:67-73. https://doi.org/10.2147/jbm.s103796.

19. Barry MJ, Edgman-Levitan S. Shared decision making: pinnacle of patient-centered care. N Engl J Med. 2012;366(9):780-1. https ://doi.org/10.1056/NEJMp1109283.
20. Shay LA, Lafata JE. Where is the evidence? A systematic review of shared decision making and patient outcomes. Med Decis Mak. 2015;35(1):114-31. https://doi.org/10.1177/0272989x14551638.

21. Nossair F, Thornburg CD. The role of patient and healthcare professionals in the era of new hemophilia treatments in developed and developing countries. Ther Adv Hematol. 2018;9(8):239-49. https://doi.org/10.1177/2040620718784830.

22. Pope C, Mays N. Reaching the parts other methods cannot reach: an introduction to qualitative methods in health and health services research. BMJ. 1995;311(6996):42-5.

23. Green J, Thorogood N. Qualitative methods for health research. Introducing qualitative methods. 3rd ed. London: Sage; 2014.

24. Lock J, de Bekker-Grob EW, Urhan G, Peters M, Meijer K, Brons $\mathrm{P}$, et al. Facilitating the implementation of pharmacokineticguided dosing of prophylaxis in haemophilia care by discrete choice experiment. Haemophilia. 2016;22(1):e1-10. https://doi. org/10.1111/hae.12851.

25. Mantovani LG, Monzini MS, Mannucci PM, Scalone L, Villa M, Gringeri A. Differences between patients', physicians' and pharmacists' preferences for treatment products in haemophilia: a discrete choice experiment. Haemophilia. 2005;11(6):589-97. https://doi.org/10.1111/j.1365-2516.2005.01159.x.

26. Smit C. Personal reflections of a patient representative in an appraisal committee. Patient. 2015;8(1):5-10. https://doi. org/10.1007/s40271-014-0086-8.

\section{Affiliations}

\section{Erna C. van Balen ${ }^{1}(1) \cdot$ Marjolein L. Wesselo ${ }^{1,2} \cdot$ Bridget L. Baker $^{1,2} \cdot$ Marjan J. Westerman $^{2}\left({ }^{\circ} \cdot\right.$ Michiel Coppens $^{3} \cdot$ Cees Smit ${ }^{1}$. Mariëtte H. E. Driessens ${ }^{5}$. Frank W. G. Leebeek ${ }^{6}$. Johanna G. van der Bom ${ }^{1,7}$ (D) Samantha C. Gouw ${ }^{1,4}$ (I)}

1 Department of Clinical Epidemiology, Leiden University Medical Center, Postzone C7-P, P.O. Box 9600, 2300 RC Leiden, The Netherlands

2 Department of Methodology and Applied Biostatistics, Vrije Universiteit Amsterdam, Amsterdam, The Netherlands

3 Amsterdam Cardiovascular Sciences, Department of Vascular Medicine, Amsterdam UMC, University of Amsterdam, Amsterdam, The Netherlands

4 Department of Pediatric Hematology, Amsterdam UMC, University of Amsterdam, Emma Children's Hospital, Amsterdam, The Netherlands
5 Netherlands Haemophilia Society (NVHP), Nijkerk, The Netherlands

6 Department of Haematology, Erasmus University Medical Center, Rotterdam, The Netherlands

7 Center for Clinical Transfusion Research, Sanquin Research, Leiden, The Netherlands 